\title{
Research on Standardization of Funeral Process based on CRM Model
}

\author{
Yun ZHANG ${ }^{1, a}$, Yong-Gang $A N^{1,2, b,{ }^{*}}$, Xiao-Yan $M A^{1,2, c}$, and Lei $\mathrm{YU}^{\mathrm{d}}$ \\ ${ }^{1}$ Department of Landscape Architecture, Beijing University of Agriculture, Beijing, China \\ ${ }^{2}$ Beijing Rural Landscape Planning and Design Engineering Technology Center, Beijing, China \\ Beijing Laboratory of Urban and Rural Ecological Environment, Beijing, China

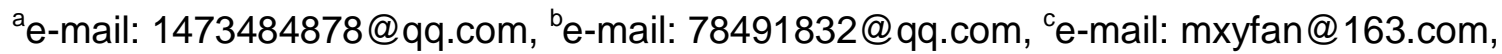 \\ de-mail: 29009071@qq.com
}

Key words: CRM, Service Standard, Before Funeral Out.

Abstract. Combined with CRM theory, considering that there is a lack of standardization in the evaluation of funeral service in all walks of life at present, establish a standard process of funeral and burial, and verify the relationship between the two.

\section{Research Background}

Funeral is a social activity of civilization to deal with the body and giving expression of their grief since the human civilization to adapt to the natural selection process.Funeral,the dead for burial after encoffined Ting, is a form of the lived mourning for the dead,for the most part is traditional etiquette.Burial,burying the body, is the processing method of the dead body,there are different kinds of burials in different regions and different ethnic groups. The funeral is the abbreviation of funeral activities and burial method.[1]

Funeral is a meaningful farewell activities uniquely taken by human to the similar that has lost its natural life, no doubt has a profound cultural content, is a particular form of a certain culture [2], embodies the people's awareness of the value, understanding and grasping of life, is the product of social development, is also an important part of cultural traditions, will always go hand in hand with the human.

Funeral originated from the clan and blood relationship, yet the funeral industry originated from the development of social economy and social division of labor. Along with the social division of labor deepening, commodity production and exchange developing to a certain extent, funeral market emerged. The gradual establishment of the market economy in our country requires the funeral service industrialized, and the funeral service organizations from the public institutions to the enterprise management. Funeral reform has made a great breakthrough in the implementation process, also shows some problems at the same time.

At present, in the folk funeral market, because of the lack of the education of folk culture in our country and the fault of traditional cultural development, a large number customers of after 70, 80, 90 lack of the understanding of the funeral and Funeral is a social activity of civilization to deal with the body and giving expression of their grief since the human civilization to adapt to the natural selection process. Funeral, the dead for burial after encoffined Ting, is a form of the lived mourning for the dead, for the most part is purchase experience of the related product, so there are asymmetries of service standards and product contents between the buyers and sellers. This is the problem that the funeral industry has for years, in other words, can't get the funeral process service standardized, then make the product provider manage the process, also provide the basis for 
the evaluation of product and service for the product purchaser.

For that reason, this research combined with the status of funeral home and cemetery of Yunnan Kunming JinFu Culture Cemetery Co., Ltd. with the mature management mode, discussing on the standardization of one-stop service for the funeral service, solving the problem by using the process mode of before the funeral out, means to manage customer relationship by informationized means, and establish a standard of the standardized process.

\section{Related Research Theory and Research Analysis}

\section{Connection between CRM Theory System and Funeral Business}

CRM stands for Customer Relationship Management, belongs to the category of management. CRM originated from "Contact Management" raised in the early 80s: a management style that is specifically designed to collect all the information that the customer and company contact. By the early 90s, it became Customer Care which include the telephone service center and support for data analysis. Has experienced nearly twenty years of continuous development, CRM is evolving and maturing, form a complete set of management theory system eventually.[3]

CRM includes three levels of meaning: management concept, management mechanism, management software and technology. The three levels is progressive. In a word, CRM is a kind of business strategy with the customer as the center, by the means of the information technology, and restructuring the work flow, in order to give the enterprise more perfect customer communication ability, and maximize the customer's profitability.

With the increasingly fierce market competition, more and more enterprises have to transfer the focus of attention from the enterprise internal products to the enterprise external customer relationship, the funeral industry is no exception in the process of market-oriented reform. In the funeral services, CRM management model is still relatively novel concept, it is a kind of marketing way that can make the management system of the funeral enterprise more integrated, the focus is more emphasis on the long-term cooperation between the cemetery and funeral and mourning families relatives rather than short-term trading behavior. How to make the dead relatives satisfied even moved to the funeral service, then make the new customers become the loyal customers, the old customers become "gold salesman" of the cemetery and funeral, and create a good reputation, has become the core task of the management of the funeral business, CRM just generated and developed on this basis.

Specifically, CRM coordinates the interactive relationship between the funeral business and mourning families in marketing, sales and service by using the corresponding information technology and Internet technology, provides customers with the personalized service of cultural life experience. Attract new customers, retain old customers and existing customers into loyal customers by implementing funeral-cemetery integration services, so as to increase market share, and comfort mourning families' grief for the dead at the same time.

In the implementation process of the CRM, the most important is to obtain customer information, analysis of customer information and make marketing decisions, for reference to the relevant departments to improve the funeral management efficiency. Experience has proved that construction of information platform for funeral management based on Cloud Computing can realize the funeral business synergy, so as to integrate the resources of all parties effectively, raise resource utilization greatly, and meet the needs of the funeral-cemetery servicing the customers.

\section{Funeral Service Industry lack of Valuable Marketing Way at present stage}

In today's highly developed computer technology, implement customer relationship management 
systematically and reduce implementation cost effectively has become possible, CRM can better serve the enterprise and its customers. In particular, because of the revolutionary development of database technology and Internet technology, many marketing status in theory can be realized in the marketing practice.

Through the analysis of the existing information funeral service resources in our country at this stage and the development opportunities of network funeral in the perspective of social change, we can clearly see that information processing in sales, marketing and service interaction of the funeral industry did not play a key role in the development of the funeral industry. The reason is that first of all, it should not be confined to the ritual link of the funeral activity, the single development of Internet worship will separate the virtual funeral and social traditional worship mode completely, so as to face the fundamental contradiction between the virtual network and social reality.[4]

\section{Value can be Achieved based on Combination of CRM and the funeral and burial services}

The combination of CRM and the funeral all in one service is to solve the split between the virtual funeral and social traditional worship mode, we must face up to the current development situation of our country's network funeral, re-examine the management of CRM and the funeral services with greater vision and more open strategic pattern, start with the funeral activities of funeral, burial and other aspects, based on the practice of information funeral platform, with the good opportunity of the cultural life networking brought by China's current social transition as the starting point at the same time, through the CRM measures online and offline, reform and improve the reality of the funeral service system, build a solid online funeral and burial system with the foundation of offline, so as to break the board for the network funeral, and give full play to the value of the combination of CRM mode and the funeral and burial services.

\section{Feasibility Analysis of the two In-depth Study}

With the rapid development of the Internet, the combination of the funeral activities and the Internet has become increasingly close. China's network funeral approached the daily life of the public quietly, among the most rapidly developing areas, including the network of funeral, especially the development of CRM electronic information and the construction of cemetery planning website.

The possibility and opportunity of the combination of community informatization construction and CRM funeral information management, social structure networking and network funeral interaction, transparent social services and life and cultural services will all become the feasibility of in-depth integration and research of CRM and the funeral service.

\section{Take Yunnan JinFu Culture Cemetery Co., Ltd. for Instance \\ Case Company Introduction}

Kunming Jinning Modern Funeral Service Co., Ltd.(funeral parlour )and JinFu Culture Cemetery Co., Ltd.(cemetery)are all private enterprise, and they are a brother relationship, are all BOT investment projects of Jinning County Civil Affairs Bureau. The two companies engage in the funeral service and cemetery sales business, under the years' joint efforts of all members of the companies, has earned their spurs in the industry.

Funeral home mainly serves Jinning County, the business of the funeral home is from the basic service set such as pure transportation, refrigerated storage, cremation, deposit and so on,to carry out the memorial service, flowers service, band, camera, wake and the etiquette Service. The 
number of cremated is more than two thousand people, operating income to millions of yuan, the company is booming.

With the growing maturity of the park construction, the improvement of plant landscaping, the diversity of the tomb area, the standardization of customer service and the deepening of marketing strategy, cemetery sales business has occupied a certain share in Kunming, Yuxi and other markets, operating income amounts to tens of millions of yuan.

Under the steady growth of the funeral service and cemetery sales, the cemetery has applied for new over-the-counter market listed for future development, will become the first shares of the funeral soon.

\section{Competitive Advantage of One-Stop Service in Funeral-Cemetery Integration}

In recent years, with the advance of the population aging, the funeral consumption subject will be transferred from after 70 to after 80 , because they have very limited experience of funeral and burial, don't know how to handle the funeral, need expert assistance, so as to provide a market demand for the one-stop service. The gradual opening of the funeral market, the entering of the private or foreign capital, resulting in the increasingly fierce competition in the funeral. With the rising living standards, funeral customers have improved the requirements of the quality of service, service content also needs to be diversified and even personalized.[5]

Under the impact of the three factors, company management class do a better combination of the funeral and burial with its own advantage of the funeral parlour and cemetery.

The competitive advantage of the funeral-cemetery integration is that all from the people-oriented, all for the funeral, all to benefit the public, don't let the mourning families contact with different units to negotiate the funeral in the most vulnerable, the most helpless situation. Meet the family members' various needs of the spirit and matter, use a specific rituals to serve a specific group of people in a given environment. Achieve the target that "A funeral free phone", "As long as you make a phone call, the rest of the things do by our company" is not an empty slogan, let the family see, touch, get and really feel the benefits of one-stop service.

Companies implement the measure that "buy a tomb, send a full set of funeral home service", have a loved one's death, just make a phone call to the staff, they will immediately get quality, considerate, thoughtful, efficient service. What you use, what we have; what you need, what we offer; as long as you are convenient, we are not afraid of trouble. In addition, all paid service such as the corpse car, corpse room and refrigerated coffin, funeral supply is provided a wider choice for mourning families according to the price of the tomb that customer purchase.

\section{Initiative Service Opportunities Before Funeral Out}

At present, there is full of social funeral intermediary in the funeral market, we do not deny the significance of the existence of the funeral intermediary, their presence makes up the function of some funeral home, of course, the intermediary also get the appropriate remuneration.

In view of this phenomenon, the company is committed to creating a professional funeral service, with professional personnel, professional equipment and professional knowledge, can provide professional, personalized service, the more important it is to accept the supervision and guidance of the Department of civil affairs, so that consumers have the right to complain. The company only provides a choice for consumers, survival of the fittest in the market will decided by the service eventually.

The company is aimed at high and mid grade funeral service market to provide the branded, quality, personalized "English Service Butler" service experience, based on the direct stores and 
franchised stores to create "thirty minutes of funeral service circle", arrive at the scene at the fastest speed to took over the scene for active service opportunities.

Before the funeral out via the Internet platform to realize the full interaction of online and offline, improve the response ability of the funeral services, achieve online and offline service platform construction, management, promotion to create "hospice" products through the model of funeral service network platform. Funeral free one-stop service system provide hospice services for mourning families to create integrated service product chain of "old, funeral, burial, fete".

\section{Use of CRM Information}

The company combines the funeral process with CRM, divides the customers into three categories: Dignity Customers, Honour Enjoy Customers and Valued Customers according to the specific steps of "Customer Indigoeyes-Processing Coffin-Hall Layout-Farewell-Ashes Buried" of the funeral process and the factors of the social economic status, consumption level and so on. And design the corresponding funeral packages for this three kinds of customers, the price was 4600 yuan, 8600 yuan and 13800 yuan. The funeral package include the five service of shuttle service, body processing service, memorial services, cremation service and hosting service, customers can select the appropriate funeral packages according to different categories.

\section{Establishment of Standardization Process}

The company has the innate advantage of the funeral-cemetery integration, then before the funeral out to attract customer, and use CRM to design suitable products, but if you can not provide satisfactory service to customers, it will become empty. This paper mainly discusses that the company spares no effort to establish standardized service processes to improve customer satisfaction.

Explain the whole process of the funeral by Figure 1, including three part of funeral, burial and fete, Hall Layout for example, including building hall, flower decoration, portrait, temporary memorial tablet and elegiac writing. Some people think that different around the burial customs, unable to establish a standardized process, in fact, for example, people may set up different forms of hall around, but it is essential to building a hall in the funeral process.

The company attaches great importance to the satisfaction of the customer service, continues to explore the optimization of the service process since the founding of the company, establishes a service process suitable for the local environment and own condition in regard to the service object, hardware equipment, staff quality, flexible deployment and other factors especially.

The following in the standard process of funeral home transportation for example shows a brief description of the content flow, the standard process is divided into five parts, respectively, work duties, work procedures, work standards, work discipline and assessment. To save space only the specific operation process that collect location is hospital morgue is listed.

I Fill the relevant information of the dead in the card according to the death certificate family members provided(the validity and legitimacy must be examined), the families confirm the remains and check the situation of remains such as the wound, the degree of corruption, the valuables carry-on, methods such as sanitary coffin, make a record and signature confirmed by the families on the card.

I Paste the card on the remains bag or sanitary coffin after the confirmation of the remains.

I When collecting the remains, the paper at the bottom of the sanitary coffin must be placed beautiful; must bow to the remains before moving it; handle with care when transporting the remains. 


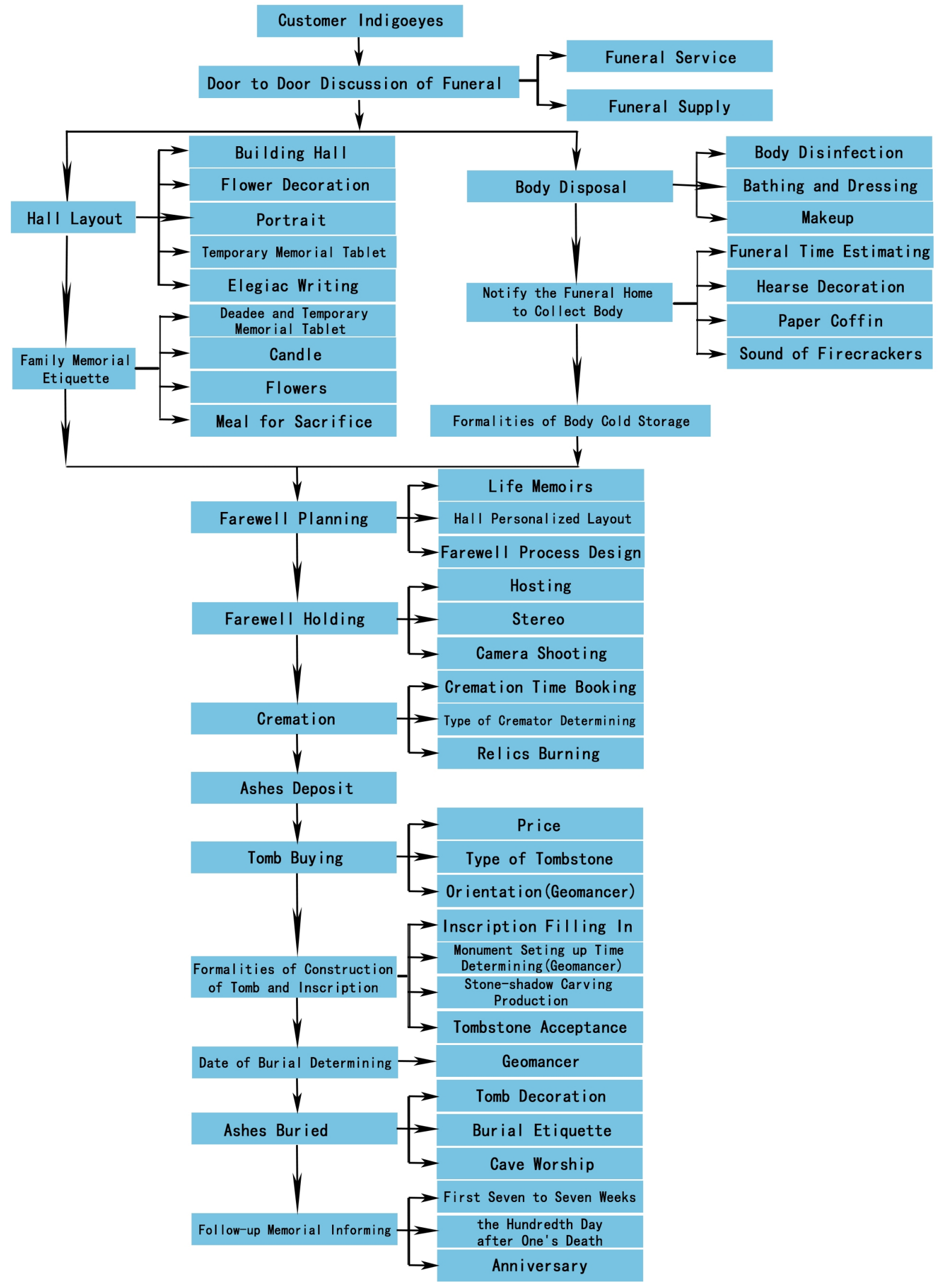

Figure 1. Flow Chart of Funeral, Burial and Fete 
I Carry the remains to the car, the families bring all the necessary items such as the ID card of the dead, the ID card of the relatives and so on, back to the funeral home.

I Must bow to the remains before move it out of the car in the funeral home, then record in the register after the completion of the work.

In addition, in view of the program is easy to make mistakes, focus on checking to prevent the error occurred. The work responsibilities, work standards and assessment tightly combined, supervise the implementation of the standard process by the staff consciously.

\section{Conclusion}

Jinfu company has the advantage of the funeral-cemetery integration, then before the funeral out for active service opportunities, put forward three different funeral packages combined with the characteristics of Jinfu customers according to the CRM theory at the same time, considering the opportunities and threats of the company's external environment and the advantages and disadvantages of their own resources, has been recognized by the vast majority of customers since establish a standard process to service customers.

For the further development of the future, Jinfu company revise the enterprise service process, enhance the quality of service personnel, ensure the service equipment usable and the goods supply adequate constantly.

In summary, combines with the CRM theory, Jinfu company puts the customer relationship management in a very important position, provides good customer service, builds a strong customer relationship and customer trust through a variety of effective measures[6], and establishes a one-stop funeral standard process gradually.

\section{Acknowledgement}

This paper is funded by Science and Technology Innovation Service Ability Construction of Urban and Rural Ecological Beijing Laboratory Project (Project Number:

PXM2016_014207_000003) and Beijing University of Agriculture, 2016 Think Tank Project

(Project Number: ZHK201610), and belongs to the projects' periodical achievements.

\section{References}

[1] Du Jing. Study on the Problems and Legal Countermeasures in the Management of Funeral Industry in China. Xinjiang University of Finance and Economics, The 2013 master's degree thesis.

[2] Gao Haisheng, Shi Guangfeng, Pei Qingfang. Connotation, Form and Characteristics of Funeral Culture. Journal of Hebei Normal University(Philosophy and Social Science Edition), Sep.2006.

[3] An Shubao. Disussion on Customer Relationship Management(CRM). Modern Intelligence, September 2005, No.9.

[4] Fei Zhongzheng, Guo Lin. Key of Online is Offline: Research on the Development of Network Funeral and Burial from the Perspective of Social Change. Gansu Social Sciences, No.1, 2004.

[5] Li Juan. Research on the Related Problems in the Process of Marketization of Funeral Industry. Hunan Normal University, master's degree thesis, Oct.2012.

[6] Lin Xiaoyuan. Disussion on Customer Relationship Management(CRM). Sun Yatsen University Forum, No.4, 2001. 